\title{
Depth trajectory and performance of a trawl used for an international bottom trawl survey in the Mediterranean*
}

\author{
JACQUES A. BERTRAND ${ }^{1}$, IOLE LEONORI ${ }^{2}$, PIERRE-YVES DREMIÈRE ${ }^{3}$ \\ and GIULIO COSIMI ${ }^{2}$ \\ ${ }^{1}$ IFREMER, Laboratoire Ecologie Halieutique, rue de l'île d'Yeu. BP 21105, 44311 Nantes cedex 03, France. \\ E-mail: bertrand@ifremer.fr \\ 2 I.R.PE.M. - CNR, Largo fiera della pesca, 60100 Ancona, Italy. \\ ${ }^{3}$ IFREMER, Service Technologie des Pêches, Av. Jean Monnet, BP 171, 34203 Sète Cedex, France.
}

\begin{abstract}
SUMMARY: An international bottom trawl survey (the MEDITS programme) has been carried out every year in the Mediterranean since 1994. During each survey, about 1000 hauls are done by a fleet of 8 to 11 vessels from 10 to $800 \mathrm{~m}$ depth, applying a unique standardized sampling protocol. This study analyses the trajectory and the performances of the sampling gear used for this survey, from records obtained during the surveys aboard some vessels in different geographical sub-areas and at different depth levels. Two kinds of sensors have been used, one to characterize a posteriori the vertical trajectory of the trawl from the beginning of shooting to the end of hauling ( 830 hauls), the other to describe in real time the stabilization of the trawl at its beginning ( 16 hauls) and its geometry during the tow ( 840 hauls). The results show the variability extent of these parameters linked with vessel, area, depth and period, illustrating their impact on the swept area estimates used for biological assessments. The results strongly suggest the inforcement of a quality strategy combining the use of rigourous sampling protocols and systematic controlling of the main parameters characterizing the trawl performance during routine surveys.
\end{abstract}

Key words: bottom trawl survey, swept area, Mediterranean, abundance estimates, catching efficiency

\section{INTRODUCTION}

Knowledge on the abundance of fish stocks and exploited ecosystems is obtained primarily by analysing commercial catch data and from research vessel surveys, the second source providing a wider scope of biological data. Neverteheless, the results of bottom trawl surveys are also inherent variables. Some of the variability is associated with the natural patterns in distribution and behaviour of the population sampled by the trawl gear (Godø, 1994).

\footnotetext{
*Received November 13, 2000. Accepted August 29, 2001.
}

Additional variability is introduced by survey protocols (Byrne et al., 1981). An important part of the measurement variability is due to the performances of the gear. Indeed, the trawl is a very complex tool, sensitive to a lot of factors linked with the vessel, the operating procedure and the environment of the gear (bottom sediment, current, depth, etc.) (Walsh and McCallum, 1995).

Swept area is an important parameter which influences the abundance estimates from bottom trawl surveys (Doubleday and Rivard, 1981; Engås, 1994; God $\varnothing$ and Engås, 1989). This swept area is defined by the geometry of the gear (for instance, 


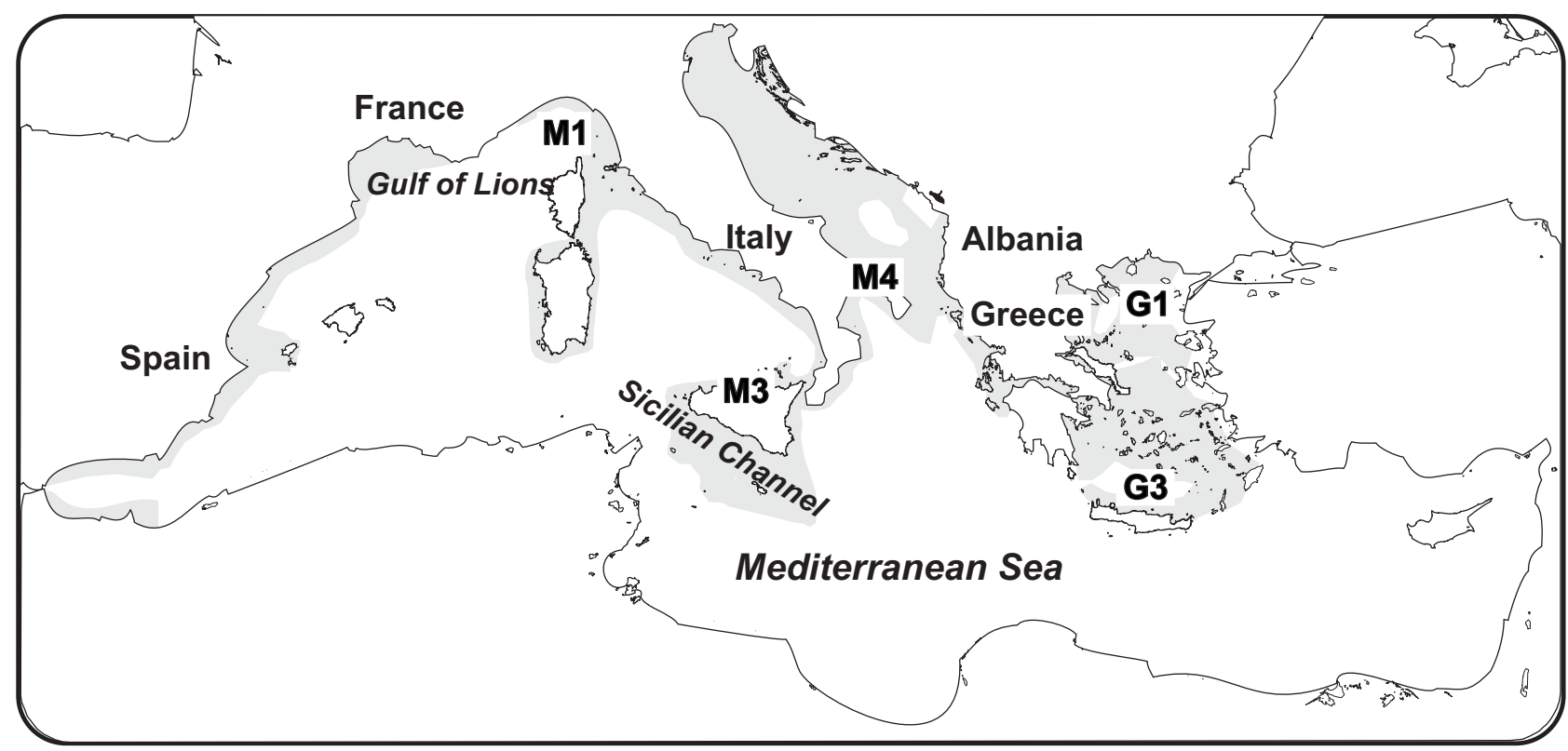

FIG. 1. - Localization of the areas cited in the paper (in grey: the area covered by the MEDITS survey in 2000, from the coast to $800 \mathrm{~m}$ depth; M1: Ligurian Sea, north and central Tyrrhenian Sea; M3: south Tyrrhenian Sea and Sicilian Channel; M4: west Ionian Sea and south Adriatic Sea; G1: north Aegean Sea; G3: south Aegean Sea).

door or wing spread) and the distance really covered by the gear in contact with the bottom. Since the availability of autonomous acoustic devices to follow up the trawl geometry (Engås and West, 1987; Wathne, 1977), a lot of studies have been done on trawl performances (Lauth et al., 1998; Lin et al., 1996; Marteinsson, 1992; McCallum and Walsh, 1995). Most of them are devoted to trawl geometry, especially to the relationship between door and wing spread and the height of the mouth (vertical distance between the middle of the headrope and the footrope level, once the bottom trawl is working on the sea ground). Trawl geometry has been studied to improve the reliability of bottom trawl surveys (Engås and Godø, 1986; Fiorentini et al., 1996). In Italy, Fiorentini et al. (Fiorentini and Cosimi, 1981; Fiorentini et al., 1994, 1998) have studied the performance and geometry of the trawls used in a national survey programme (GRUND) covering the whole Italian coast. Nevertheless, little information is available on the effective distance covered by the trawl in contact with the bottom.

In the Mediterranean, an international bottom trawl survey programme has been carried out every year since 1994 to assess the benthic and demersal resources along the coasts of the western and northern part of the basin (Bertrand et al., 2000a, 2002). The different vessels involved in the survey programme (between 8 to 11 according to the year) used one unique standardized gear and sampling protocol since the beginning of the project. A technologist team (IFREMER - IRPEM) has been associated with the programme since its beginning. After conceiving and setting the sampling trawl, this team has already analysed different items linked with the performances of the gear, like its efficiency (Fiorentini et al., 1999) and escapement of some species from its main body (Dremière et al., 1999). The results obtained have been used to improve the common MEDITS sampling protocols.

The aim of this paper is to analyse the trajectory (in a vertical plane) of the trawl during the MEDITS surveys, to give some information on the geometry of the trawl, to look at the effects on swept area estimates, and formulate some recommendations for inclusion of the obtained results when assessing demersal resources from trawl surveys.

\section{MATERIAL AND METHODS}

\section{Source of data}

During each MEDITS yearly routine survey, about 1000 hauls were done aboard 8 to 11 vessels according to the year (i.e. more than 7500 hauls since 1994 to 2000), covering the north-west part of the Mediterranean (Fig. 1). The surveys were carried out simultaneously aboard a few $\mathrm{R} / \mathrm{V}$ vessels ( 2 or 3 according to the year) and chartered stern trawlers (Table 1). 
TABLE 1. - Main characteristics of the vessels used for the MEDITS surveys and considered in this study. R/V: research vessel; F/V: fishing vessel; LOA: length overall.

\begin{tabular}{|c|c|c|c|c|c|c|}
\hline Vessel name & Type & LOA (m) & Gross tonnage $(\mathrm{t})$ & Material & Power $(\mathrm{kW})$ & Warp diameter $(\mathrm{mm})$ \\
\hline Cornide de Saavedra & $\mathrm{R} / \mathrm{V}$ & 66.7 & 1524 & steel & 1651 & 29 \\
\hline Francesco Padre & $\mathrm{F} / \mathrm{V}$ & 25 & 88 & steel & 660 & 14 \\
\hline Ioannis Rossos & $\mathrm{F} / \mathrm{V}$ & 26.3 & 115 & iron & 368 & 12 \\
\hline L'Europe & $\mathrm{R} / \mathrm{V}$ & 29.6 & 259 & aluminium & 690 & 16 \\
\hline Nautilos & $\mathrm{F} / \mathrm{V}$ & 28.4 & 138 & iron & 600 & 14 \\
\hline Kapetan Paraschos & $\mathrm{F} / \mathrm{V}$ & 26.1 & 85 & wood & 386 & 12 \\
\hline Pasquale e Cristina & $\mathrm{F} / \mathrm{V}$ & 33.1 & 158 & wood & 923 & 16 \\
\hline Sant'Anna & $\mathrm{F} / \mathrm{V}$ & 32.2 & 97 & steel & 1357 & 14 \\
\hline
\end{tabular}

All the surveys were conducted using the same standardized protocol (Anon., 1998) published according to the manual distributed to the teams before the surveys, and their later improvements (Anon., 1999), taking into account first analysis of the gear efficiency (Dremière et al., 1999; Fiorentini et al., 1999). The trawl used for these surveys is the GOC73 made with two panels and sides, with a footrope of $28.2 \mathrm{~m}$. The protocol related to the standard gear used aboard all the survey vessels includes all the materials and their rigging arrangement from the doors to the cod end. The same gear and rigging (Table 2) are used for all the survey areas, from 10 to $800 \mathrm{~m}$ depth, except the sweeps which were systematically lengthened of $50 \mathrm{~m}$ down to $200 \mathrm{~m}$ depth. Furthermore, the standard tow duration is 30 minutes up to $200 \mathrm{~m}$ depth and 60 minutes for deeper waters. In the protocol, the standard speed of the gear over the ground is fixed at 3 knots. Nevertheless, when speed indication is not available, the officer has to adjust the vessel speed to the best of his ability taking into account water currents and side wind.

TABLE 2. - Characteristics of the MEDITS trawl and rigging.

\begin{tabular}{ll}
\hline Device & Main characteristics \\
\hline Trawl & \\
Type GOC73 & Sampling bottom trawl, made of four panels \\
Floatline length & $35.70 \mathrm{~m}$ \\
Groundrope length & $40.00 \mathrm{~m}$ \\
Sideropes length & $7.40 \mathrm{~m}$ \\
Wings meshsize & $140 \mathrm{~mm}$ (stretched) \\
Codend meshsize & $20 \mathrm{~mm}$ (stretched) \\
& \\
Rigging & Morgère WH type; $2.5 \mathrm{~m} ; 350 \mathrm{~kg}$ each one \\
Doors & Combination rope; diameter: $32 \mathrm{~mm}$ \\
Sweeps & Length: $100 \mathrm{~m}(10-200 \mathrm{~m}$ depth) \\
& Length: $150 \mathrm{~m}(200-800 \mathrm{~m}$ depth) \\
Upper bridles & Steel wire; diameter: $10 \mathrm{~mm}$; length: $30 \mathrm{~m}$ \\
Lower bridles & Combination rope; diameter: $32 \mathrm{~mm}$; length: \\
& $29 \mathrm{~m}+1 \mathrm{~m}$ chain \\
Floats & $40 \mathrm{x} 2.7 \mathrm{kgf}$ \\
Sinker chains & $3 \times 40 \mathrm{~kg}+15 \mathrm{~kg}$ \\
\hline
\end{tabular}

The official start of the haul is defined as the moment when the gear geometry is stabilized on the bottom. Some indications are given to the watch officer to standardize the end of shooting operation in order to ensure a good contact of the trawl with the bottom, from the start of haul. Aboard vessels without equipment to watch in real time the gear geometry, this moment is left to the watch officer's judgement, as well as the ship speed during shooting and the warp shooting speed itself.

\section{Depth trajectory characterization}

From 1998, the use of the Minilog system (Vemco) has been generalized aboard all the vessels to record a posteriori water temperature and depth at the trawl level. The recorder was fixed on the central upper panel of the gear, just behind the headrope bosom. The data used to study the trawl trajectory came from depth/time Minilog records registered during the surveys 1998 to 2000 aboard six vessels (Table 3) in different areas of the MEDITS zone (Fig. 1). Detailed data were available for 363 of 830 hauls analysed; the data taken into account were continuous from the start of shooting to the end of warps retrieving (and later on), with one record each 30 seconds to 2 minutes depending on the vessel. For the other hauls, only characteristic points of the trajectory have been used. All the hauls analysed were declared valid by the teams on board.

Two types of data available from the navigation bridge have been taken into account: the official times of start and end of the hauls, and the depth recorded from the navigation bridge sounder at the official start and end of haul. Aboard most of those vessels, the official start of haul was defined in relation to the end of warp shooting (more or less close to the corresponding time, according to the depth). Only aboard the vessels using a system 
TABLE 3. - Haul data used for the study (for sub-areas cf. Fig. 1; validity: as declared by the teams on board).

\begin{tabular}{|c|c|c|c|c|c|c|}
\hline Item & Vessel & Area & Year & Device & $\begin{array}{c}\text { Number o } \\
\text { Valid }\end{array}$ & $\begin{array}{l}\text { hauls studied } \\
\text { Non valid }\end{array}$ \\
\hline Trajectory & Pasquale e Cristina & Albania & 1998 & Minilog & 37 & 0 \\
\hline Trajectory & Pasquale e Cristina & Albania & 1999 & Minilog & 39 & 0 \\
\hline Trajectory & Pasquale e Cristina & Italy-M4 & 1998 & Minilog & 71 & 0 \\
\hline Trajectory & Pasquale e Cristina & Italy-M4 & 1999 & Minilog & 72 & 0 \\
\hline Trajectory & Kapetan Paraschos & Greece-G1 & 1999 & Minilog & 47 & 0 \\
\hline Trajectory & Nautilos & Greece-G3 & 1999 & Minilog & 53 & 0 \\
\hline Trajectory & L'Europe & France & 1999 & Minilog & 16 & 0 \\
\hline Trajectory & L'Europe & France & 2000 & Minilog & 42 & 0 \\
\hline Trajectory & Francesco Padre & Italy-M1 & 1998 & Minilog & 119 & 0 \\
\hline Trajectory & Francesco Padre & Italy-M1 & 1999 & Minilog & 152 & 0 \\
\hline Trajectory & Sant'Anna & Italy-M3 & 1998 & Minilog & 74 & 0 \\
\hline Trajectory & Sant'Anna & Italy-M3 & 1999 & Minilog & 108 & 0 \\
\hline Stabilization & Sant'Anna & Italy-M3 & 1995 & Scanmar & 16 & 0 \\
\hline Geometry & L'Europe & France & 1994 & Scanmar & 85 & 2 \\
\hline Geometry & L'Europe & France & 1995 & Scanmar & 74 & 0 \\
\hline Geometry & L'Europe & France & 1996 & Scanmar & 77 & 0 \\
\hline Geometry & L'Europe & France & 1997 & Scanmar & 69 & 0 \\
\hline Geometry & L'Europe & France & 1998 & Scanmar & 90 & 1 \\
\hline Geometry & Ioannis Rosso & Greece & 1994 & Scanmar & 78 & 7 \\
\hline Geometry & Ioannis Rosso & Greece & 1996 & Scanmar & 36 & 1 \\
\hline Geometry & Cornide de Saavedra & Spain & 1995 & Scanmar & 105 & 6 \\
\hline Geometry & Cornide de Saavedra & Spain & 1996 & Scanmar & 105 & 2 \\
\hline Geometry & Cornide de Saavedra & Spain & 1997 & Scanmar & 100 & 2 \\
\hline
\end{tabular}

to control the gear geometry (a SCANMAR device) (i.e. more particularly the R/V " $L$ ' $E u$ rope" and "Cornide de Saavedra"), the official start of haul was defined from direct follow-up of the trawl motion.

\section{Gear stabilization and geometry}

The data used to analyse the stabilization delay of the MEDITS gear were obtained from tests carried out in the Sicilian Channel (MEDITS area ITM3) (Fig. 1, Table 3) in May 1995 on board the professional trawler "Sant'Anna". These tests were part of a study (Fiorentini et al., 1996) devoted to properly set the sampling trawl used aboard the Italian vessels taking part in the MEDITS surveys. For these tests, the gear was rigged following the 1995 MEDITS protocol (Anon., 1998), and the hauls were carried out at different bottom depths ranging from $38 \mathrm{~m}$ to $420 \mathrm{~m}$.

Since the beginning of the MEDITS programme, a SCANMAR device was systematically used aboard 4 vessels to check the trawl geometry during the surveys, that is to say for about $25 \%$ of the hauls as a whole. The data used in this paper to analyse the geometry of the MEDITS trawl came from recordings collected during the MEDITS surveys in 1994, 1995 and 1996 aboard three of these vessels ("Cornide de Saavedra", "Ioannis Rosso" and "L'Europe”) (Table 3; Fig. 1).

\section{Data analysis}

\section{Depth trajectory characterization}

The Minilog recordings, available since 1998, allow for the follow up of the whole motion of the gear in the water column from the start of shooting to the end of hauling. From the resultant curve and the information available from the bridge, the following series of points and values have been considered to characterize the trawl trajectory during a haul (Fig. 2): $\left(\mathrm{t}_{1}\right)$ trawl shooting start; $\left(\mathrm{t}_{2}\right)$ trawl descent start (corresponding roughly to doors immersion); $\left(\mathrm{t}_{3}\right)$ trawl (footrope bosom) first contact with bottom; $\left(\mathrm{t}_{4}\right)$ official start of haul; $\left(\mathrm{t}_{5}\right)$ official end of haul, usually associated with the beginning of warp rewinding; $\left(\mathrm{t}_{6}\right)$ trawl (footrope bosom) last contact with bottom; $\left(\mathrm{t}_{7}\right)$ end of warp rewinding; $\left(\Delta \mathrm{t}_{1}=\mathrm{t}_{3}-\mathrm{t}_{2}\right)$ descent duration; $\left(\Delta \mathrm{t}_{2}=\mathrm{t}_{4}-\mathrm{t}_{3}\right)$ gap between first contact of trawl with bottom and official start of haul (positive if $t_{3}$ occurs before $t_{4}$, and negative in the opposite situation); $\left(\Delta \mathrm{t}_{3}=\mathrm{t}_{6}-\mathrm{t}_{5}\right)$ latent period; $\left(\Delta \mathrm{t}_{4}=\mathrm{t}_{5}-\mathrm{t}_{3}\right)$ effective haul duration; $\left(\Delta \mathrm{t}_{5}=\mathrm{t}_{5}-\mathrm{t}_{4}\right)$ official haul duration.

In some cases, the position of point $t_{3}$ does not appear clearly on the trajectory line. In these cases, it has been defined visibly on the curve. Furthermore, the contact with the bottom may be not permanent during the whole haul duration inducing an uncertainty on the exact contact duration. 


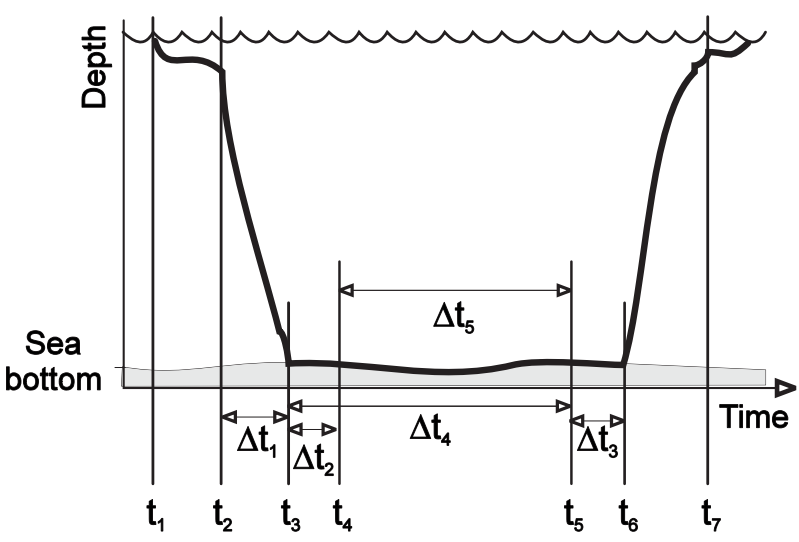

FIG. 2. - Theoretic trajectory of a gear from trawl shooting to end of warp retrieving (notations in the text).

When studying the relationships between trajectory parameters, different fittings have been tested. Finally, linear fittings have been chosen as they gave the best coefficient of determination. The fittings have been made excluding atypical values, i.e. those which were strongly far from the main distribution of the points, illustrating an abnormality in the trawl trajectory.

\section{Gear stabilization and geometry}

When underwater instruments (SCANMAR system) have been used to control the fishing operations in real time, they have given data on the geometric characteristics of the MEDITS fishing gear. The parameters usually measured on the gear were: door spread, wing spread (i.e. horizontal net opening, defined as upper net wing-end spread), vertical net opening (defined as height of the headline centre above the sea bed). The instruments were usually connected to a portable computer that recorded all

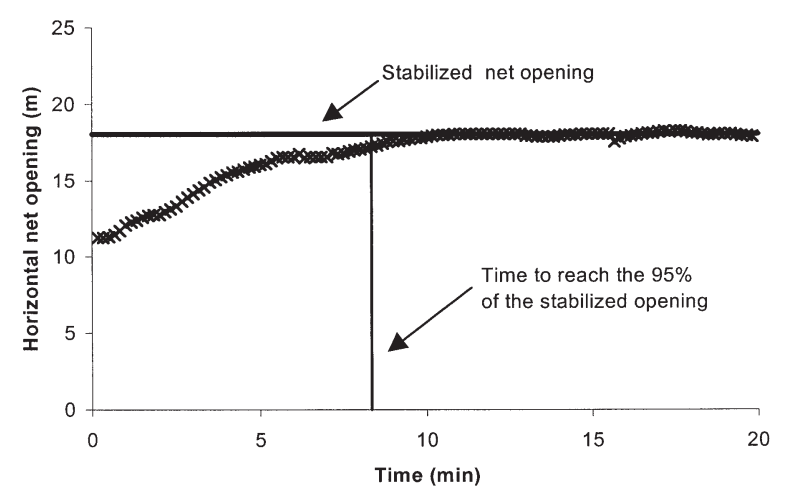

FIG. 3. - Characteristic parameters used to analyze wing spread stabilization (example from a haul aboard the "Sant'Anna" in 1995 at $200 \mathrm{~m}$ depth; warp length: $850 \mathrm{~m}$; time 0: end of warp unwinding). measurements on a hard disk (about every $10 \mathrm{sec}-$ onds, according to the vessel).

To analyse the delay for wing spread stabilization, we used an approach including the following characteristic parameters (Fiorentini et al., 1994): the time-zero point (Fig. 3) corresponds to the moment when the warps were completely paid out and the winch stopped; the setting time of the gear (the time required by the trawl to reach the correct openings after the winch stop) was defined as the time to reach $95 \%$ of the stabilized value (mean value during the haul). For each haul, the stabilized value was the average of the data registered after stabilization of gear performance (the achievement of optimal gear opening).

The parameter used to assess the variability of horizontal trawl opening was the average wing spread estimated from SCANMAR recordings for each of the 840 studied hauls (Table 3). Furthermore, a relationship between wing spread and depth has been estimated from the mean standard scope ratio defined in the MEDITS protocols (Anon., 1998) and the relationship between warp length and wing spread adopted by the MEDITS teams in swept area estimations when no direct observations in real time were available as wing spread values. This relation was calculated through the following asymptotic function (Souplet, 1995):

$$
\mathrm{E}=17.45613\left(1-\mathrm{e}^{-0.33243((\mathrm{~L} / 100)+3.60468)}\right)
$$

with E: wing spread (m) and L: warp length (m).

The comparisons of regression lines have been made with the general linear model (GLM) that encompasses both analysis of variance and regression, using the SPSS 10.0 statistical software package.

\section{RESULTS}

\section{Global results on the depth trajectory}

The official duration of a majority of hauls (76\%) agreed exactly with the standard haul durations defined in the MEDITS protocols (30 minutes and 60 minutes, depending on the depth; Fig. 4) (Anon., 1998). The other values corresponded to hauls shortened by the watch officer due to particular reasons (bottom obstruction, sudden depth variation, etc.).

The official duration values were most often higher than the effective ones. Indeed, without SCANMAR device, it was common to declare the 


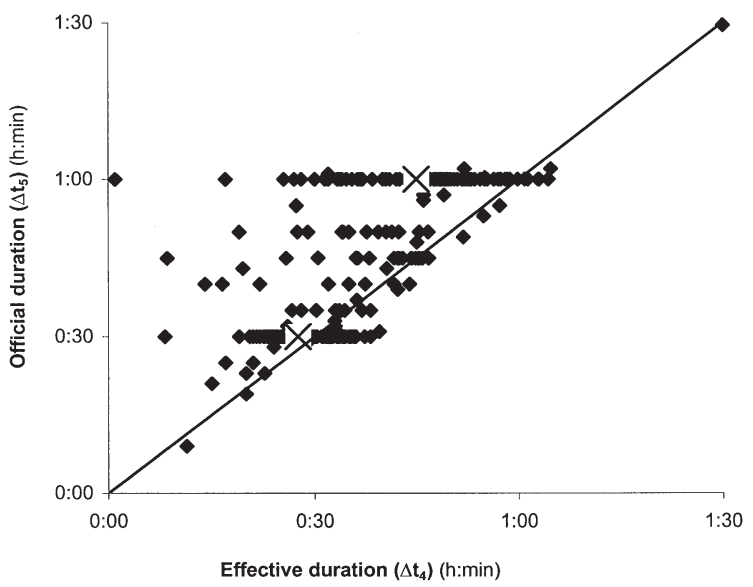

FIG. 4. - Relationship between official and effective haul duration for the 363 hauls for which this information was available ("Pasquale e Cristina" 1998 and 1999, "Kapetan Paraschos" 1999, "Nautilos" 1999 and "L'Europe" 1999 and 2000; ×: mean values for $\Delta \mathrm{t}_{5}$ respectively equal to 30 and 60 minutes; on the graph, several points may be superimposed, particularly close to the standard values).

official start of haul before the first contact of the trawl with the bottom. For depths over $200 \mathrm{~m}$ depth (haul duration 60 minutes), the mean effective duration of hauls was $28 \%$ less than the foreseen one ( mean $=45$ minutes; S.D. $=12$ minutes). On the shelves (up to $200 \mathrm{~m}$, haul duration 30 minutes), bias was less important $(16 \%$; mean $=28$ minutes; S.D. $=4$ minutes).

This general trend integrated different types of situations that can be identified from analyses done vessel by vessel. The main variations may be highlighted from analysis of the gear descent from the sea surface to the bottom $\left(\Delta \mathrm{t}_{1}\right)$, and the gap between effective and theoretical first contact of the trawl with the bottom $\left(\Delta \mathrm{t}_{2}\right)$.

Usually, the regression of the gear descent duration $\left(\Delta \mathrm{t}_{1}\right)$ vs. depth was good $\left(\mathrm{R}^{2}\right.$ in general better than 0.90; Fig. 5), when excluding a few atypical long durations. The importance of unexpected values was variable, between $0-11 \%$ (mean $6 \%$ ) of the total number of hauls by series, according to the vessel and year. The average descending speed of the trawl between the surface to $500 \mathrm{~m}$ depth was $21 \mathrm{~m} / \mathrm{min}$. The average speeds were set between the extreme values of 17 and $30 \mathrm{~m} / \mathrm{min}$ depending on the vessel and year. At shallow depths, the results may be altered by inaccuracy in equipment calibration between the bridge sounder (particularly transducer draught) and clock, and the ones of the Minilog sensor (also in time and depth). Even on relatively shallow areas (less than $200 \mathrm{~m}$ ), a dispersion of the $\Delta \mathrm{t}_{1}$ values around the mean could be observed.
The eight regression lines shown in Fig. 5 (excluding atypical points: outliers) were compared with a GLM procedure. The depth was included as a covariate and the survey (vessel-area-year) as a factor in the model. The assumption of equality of regression slopes was tested by fitting a model containing the effects of survey and depth and the survey $\times$ depth interaction. The interaction term provided the test of the null hypothesis of equal slopes. The survey $\times$ depth interaction term was highly significant $(\mathrm{F}=28.547, \mathrm{p}<0.001)$ evidencing the inequality of the regressions.

The main effects of survey and depth within each type of survey were studied with a model incorporating separate slopes. The survey term $(\mathrm{F}=33.80, \mathrm{p}$ $<0.001)$ and the survey $\times$ depth interaction term $(\mathrm{F}=$ $621.39, \mathrm{p}<0.001)$ were highly significant. Therefore for each survey there was an estimate simple slope (the intercept and slope coefficients of the regression model are respectively estimated from the survey and survey $\times$ depth coefficients), as in Fig. 5. The estimated slope coefficients were all highly significant confirming the correlation between $\Delta \mathrm{t}_{1}$ and depth for each survey.

The results in the GLM clearly indicated a highly significant difference among regression lines of different vessels and/or years. To identify which line differs from another, different pairs of surveys were compared. The regressions for 1999 and 2000 of France ("L'Europe"; F= 3.126, p = 0.083) were not significantly different, also for Albania 1998 and France $2000(\mathrm{~F}=0.055, \mathrm{p}=0.815)$, and for Italy 1998 and France 1999 ( $F=0.824, p=0.367)$. In return, there were significant differences between the slope of the regression lines of Albania for 1998 and 1999 ( $\mathrm{F}=49.467, \mathrm{p}<0.001)$, of Italy ("Pasquale e Cristina" vessel) for 1998 and 1999 ( $\mathrm{F}=68.876, \mathrm{p}$ $<0.001$ ), of Greece (1999) for the two different vessels ("Kapetan Paraschos" and "Nautilos"; F= $12.748, \mathrm{p}=0.001$ ), and for each other combination.

In most of the studied cases, the watch officer fixed the official start of the haul before the trawl had begun to be in contact with the bottom (negative values of $\Delta t_{2}$; Fig. 6). Furthermore, the gap strongly increased with depth. This situation may directly induce a cutting down of the effective haul duration (cf. Fig. 4). Even when excluding atypical points that evidently corresponded to «bad» tows, the correlation between the two parameters was most often poor ( $\mathrm{R}^{2}$ usually less than 0.75$)$. In another way, the bad relationship for the R/V "L'Europe" may be associated with the determination of the official start 

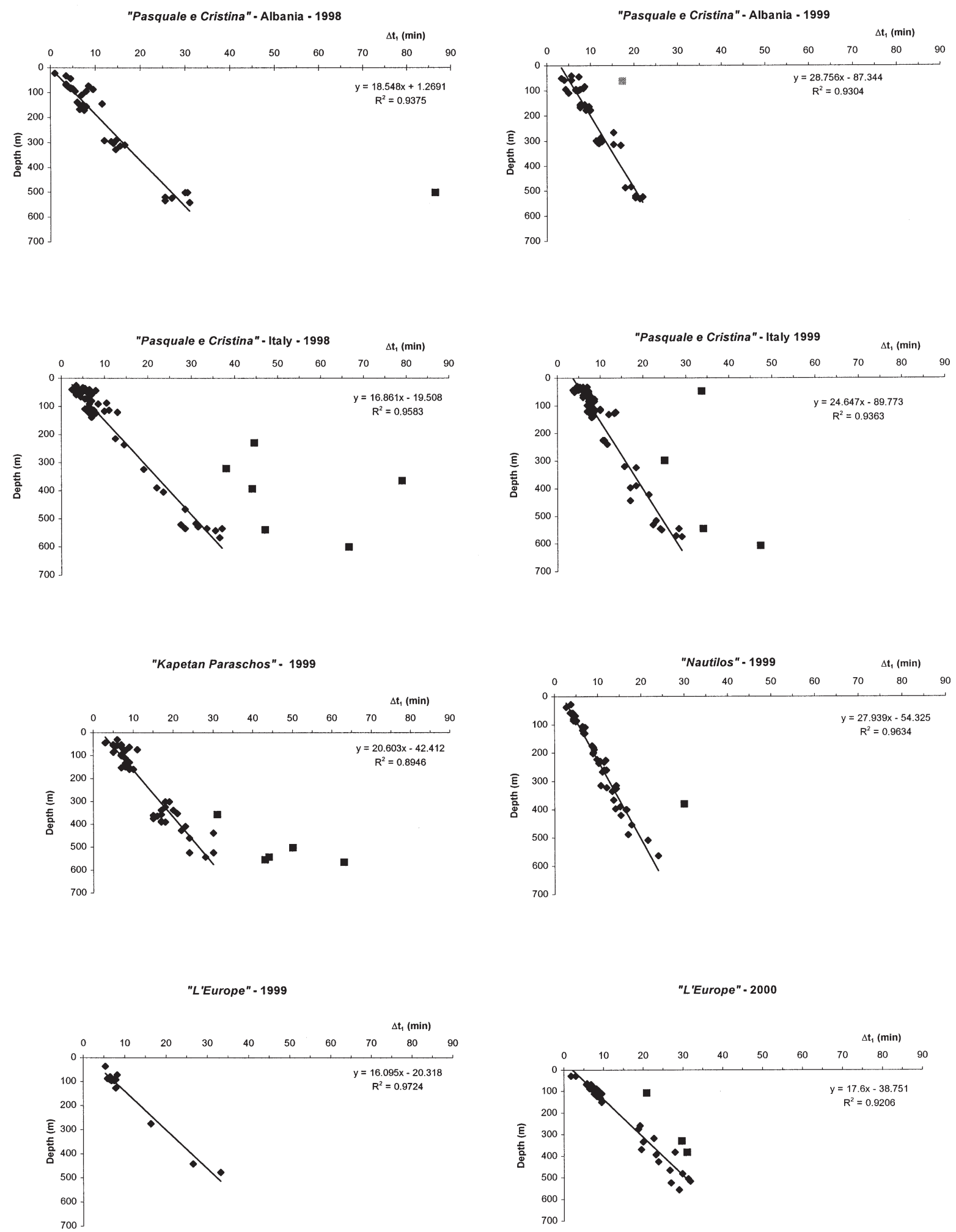

FIG. 5. - Descending motion duration of the trawl for different vessels and areas from the moment at which the trawl begins to go down and the one at which it is in first contact with the bottom, plus linear regression fitted to the data $\left(\Delta \mathrm{t}_{1} ; \diamond:\right.$ standard hauls; $\mathbf{\square}$ : atypical values excluded for the regression, definition in the text).

of the haul from SCANMAR data, and not only from the end of warp unwinding. Indeed, when the trawl performance is followed with a SCANMAR, the watch officer may delay the official start of haul till the trawl geometry stabilisation, after the first contact of the trawl with the bottom. Furthermore, 

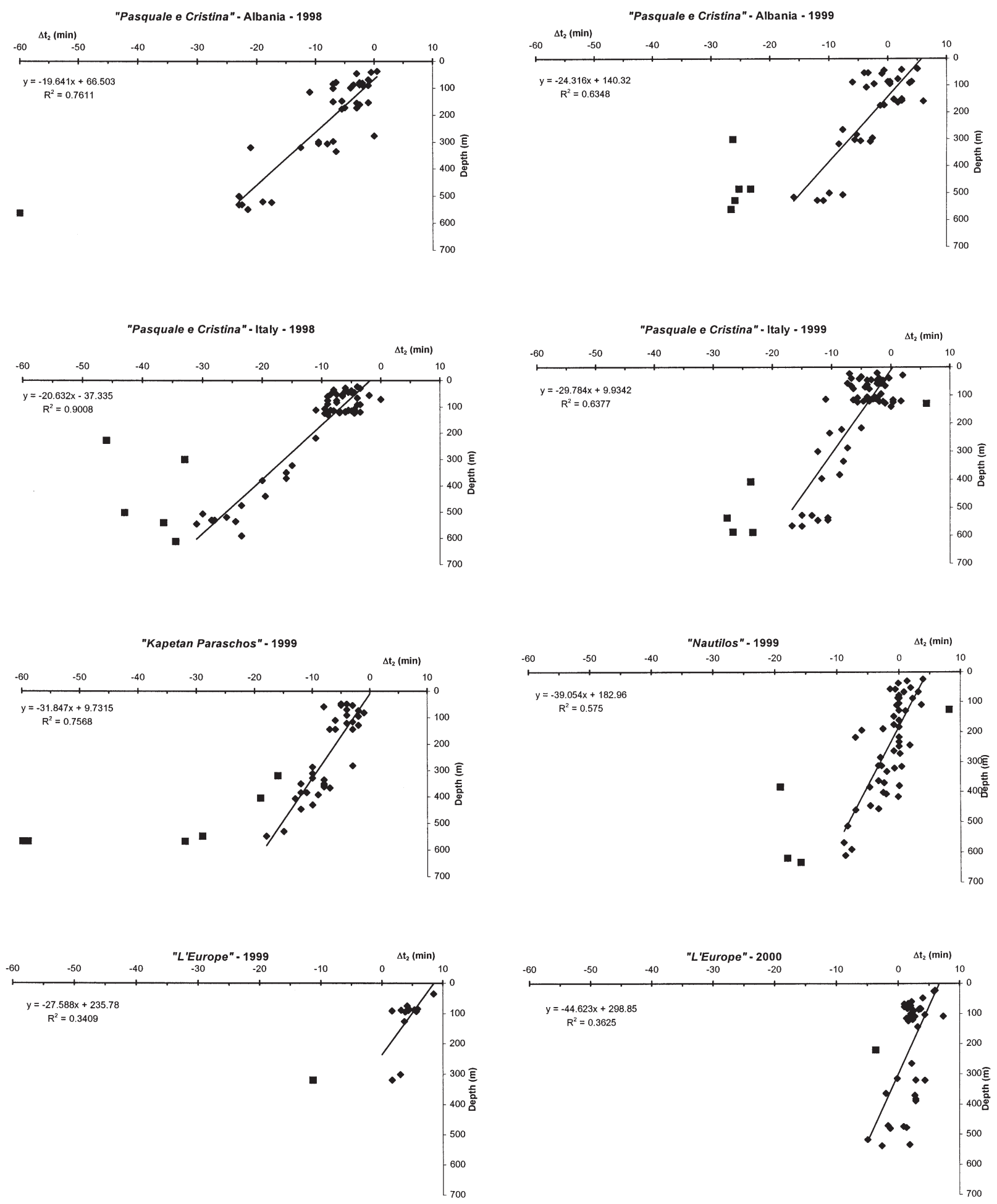

FIG. 6. - Temporal gap between the first trawl contact with the bottom, and the official start of the haul for different vessels and areas, plus linear regression fitted to the data $\left(\Delta \mathrm{t}_{2} ; \diamond\right.$ : standard hauls; $\boldsymbol{\square}$ : atypical values excluded for the regression, definition in the text).

mainly due to crew and watch officer habits during shooting, the slope of the regression was variable when comparing boats and/or years.

A GLM analysis was made on the data of Fig. 6 (excluding atypical points: outliers), using $\Delta \mathrm{t}_{2}$ as dependent variable. The survey $\times$ depth interaction term was highly significant $(\mathrm{F}=27.817, \mathrm{p}<0.001)$, evidencing the inequality of regressions.

A model incorporating separate slopes was estimated to study the effects of survey and depth with- 
in each type of survey. The survey term $(\mathrm{F}=17.192$, $\mathrm{p}<0.001)$ and the survey $\times$ depth interaction term $(\mathrm{F}=134.814, \mathrm{p}<0.001)$ were highly significant, confirming the existence of different regression lines between the surveys.

The estimated slope coefficients were all significant, so was the correlation between $\Delta \mathrm{t}_{2}$ and depth for each survey except for France (' $L$ 'Europe") $1999(\mathrm{t}=-1.490, \mathrm{p}=0.137)$. The bad linear relation between $\Delta t_{2}$ and depth $\left(R^{2}=0.34\right)$ for this survey must be related to the low number of data (only 14 data points).

As for the previous set of data, different pairs of vessels and/or years were compared to identify which regression line differed from one another, excluding France 1999. The regressions for Albania 1998 and Italy $1998(\mathrm{~F}=1.288, \mathrm{p}=0.259)$, and for Albania 1999 and Italy $1999(\mathrm{~F}=1.548, \mathrm{p}=0.217)$ were not significantly different. But the differences were significant between the slopes of the regression lines of Albania for 1998 and $1999(\mathrm{~F}=7.372, \mathrm{p}=0.008)$, of Italy ("Pasquale e Cristina") for 1998 and 1999 ( $\mathrm{F}=62.683$, $\mathrm{p}<0.001$ ), of the two Greek vessels ("Kapetan Paraschos" and "Nautilos") in 1999 (F = 7.410, p = 0.008 ), and for each other combination.

The gap between the official and the effective start of the haul was in general a few minutes closer to zero in the shallowest waters. It might strongly increase, with big variations between vessels, for the largest depths. So far, for $500 \mathrm{~m}$ depth, the advance of official start of haul $\left(\Delta \mathrm{t}_{2}\right)$ was on average 15 minutes, with a very small gap (close to zero) for some vessels (e.g. "Nautilos" and particularly " $L$ 'Europe") and a bigger one (up to almost 50 percent of the total haul duration) for others. Probably linked with an increase of the gear descent speed (from 18 to $24 \mathrm{~m} / \mathrm{min}$ in average), the gap between the official and the effective start of the haul was reduced between 1998 and 1999 aboard the "Pasquale $e$ Cristina" (approximately 25 percent of gap reduction at $500 \mathrm{~m}$ depth).

\section{Specific haul trajectories}

Most of the hauls presented a vertical trajectory close to the standard one (Fig. 7). For the hauls with a gap between official and effective starts, different situations might occur. One very extreme case was that of hauls during which the trawl was never in contact with the bottom (stopping its descending motion about tens of metres from the bottom), or finishing it's descent only at the end of the haul with

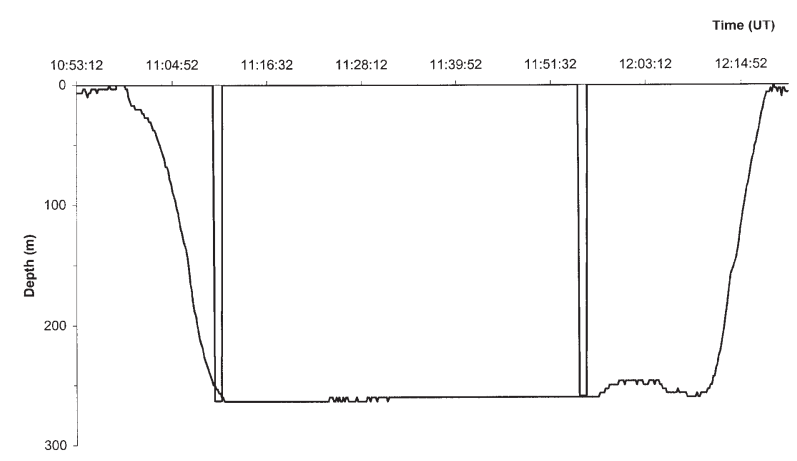

FIG. 7. - A standard trawl vertical trajectory of the gear in relation with time (on the main curve; the sharp lines indicate the official start $-\mathrm{t}_{4}$ in Fig. 2 - and end - $\mathrm{t}_{5}$ in Fig. 2 - of haul as well as the depth recorded by the bridge sounder at this moment; "Nautilos" 1999 , haul No 5).

the change in the warp tension at the beginning of warp rewinding. Sometimes, the gear had normally reached the bottom, eventually with some delay according to the official start of haul, then the trawl flew up before presenting a stabilized trajectory. Finally, some trajectories showed that, particularly in deep waters, the descending speed of the trawl was irregular, with a fastest speed at the beginning and a slowing one later on.

It may happen that hauls have to be carried out on bottoms with a sharp slope. In some areas, for instance in the Gulf of Lions where the upper slope is crossed by deep canyons, the only available way for trawling is to make them in the main slope direction. Then, the warp length has to be adjusted during the haul to ensure the good scope ratio, taking into account that the depth recorded by the bridge echosounder may be far before the one at the trawl level. In other places, it is possible to maintain the vessel along a contour line. In this situation, it may occur that the gear slips laterally towards deeper places than the ones flown over by the vessel. This kind of situation may significantly introduce a gap

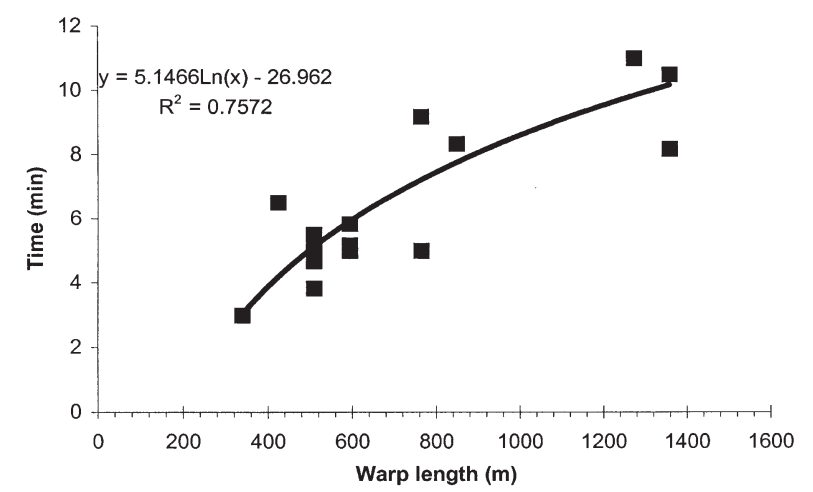

FIG. 8. - Observed time to reach $95 \%$ of the stabilized wing spread vs. warp length ("Sant'Anna” 1995, 16 hauls). 

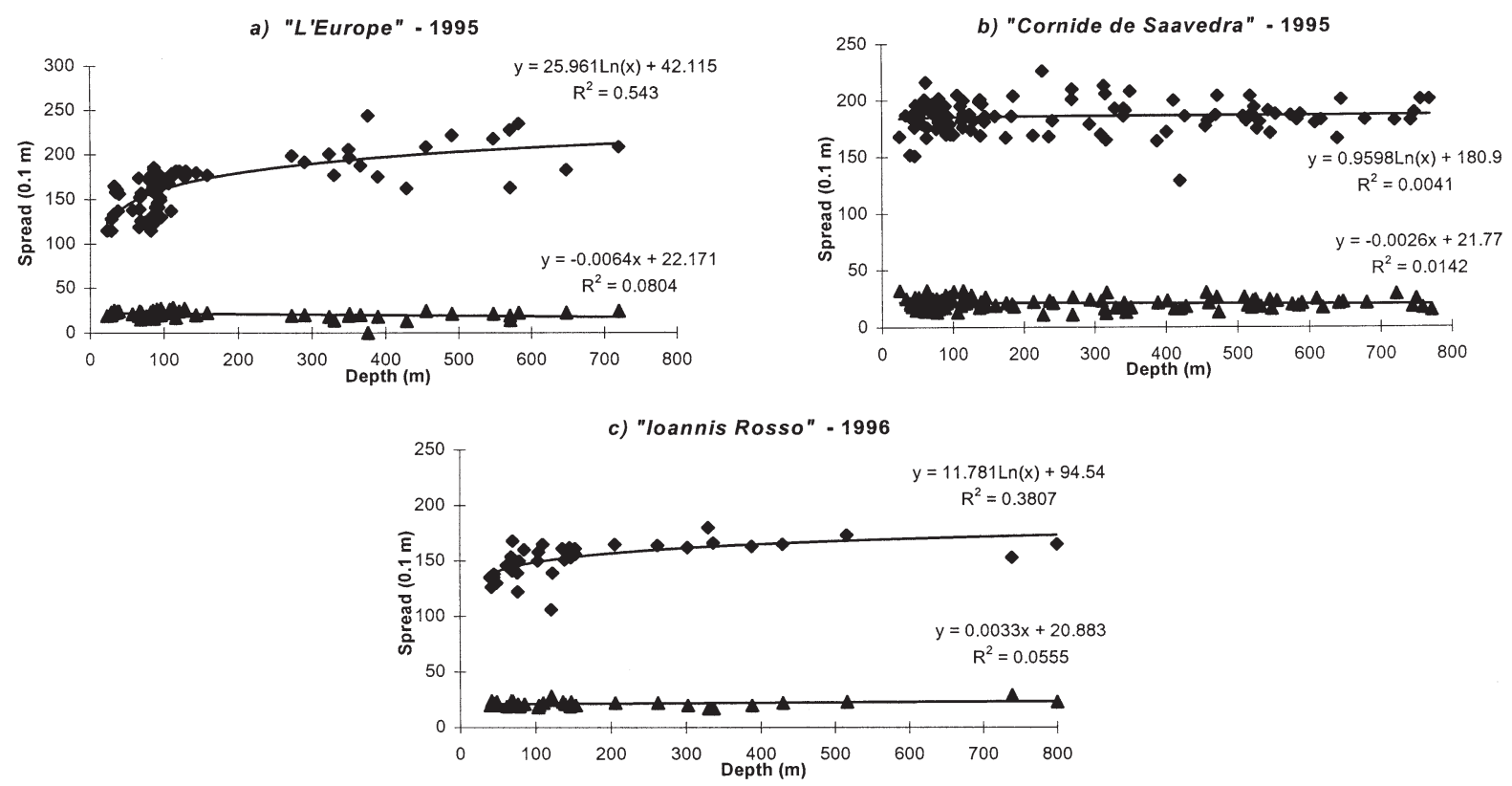

FIG. 9. - Wing spreads $(\diamond)$ and vertical openings $(\boldsymbol{\Delta})$ recorded aboard some vessels during routine surveys in relation with depth.
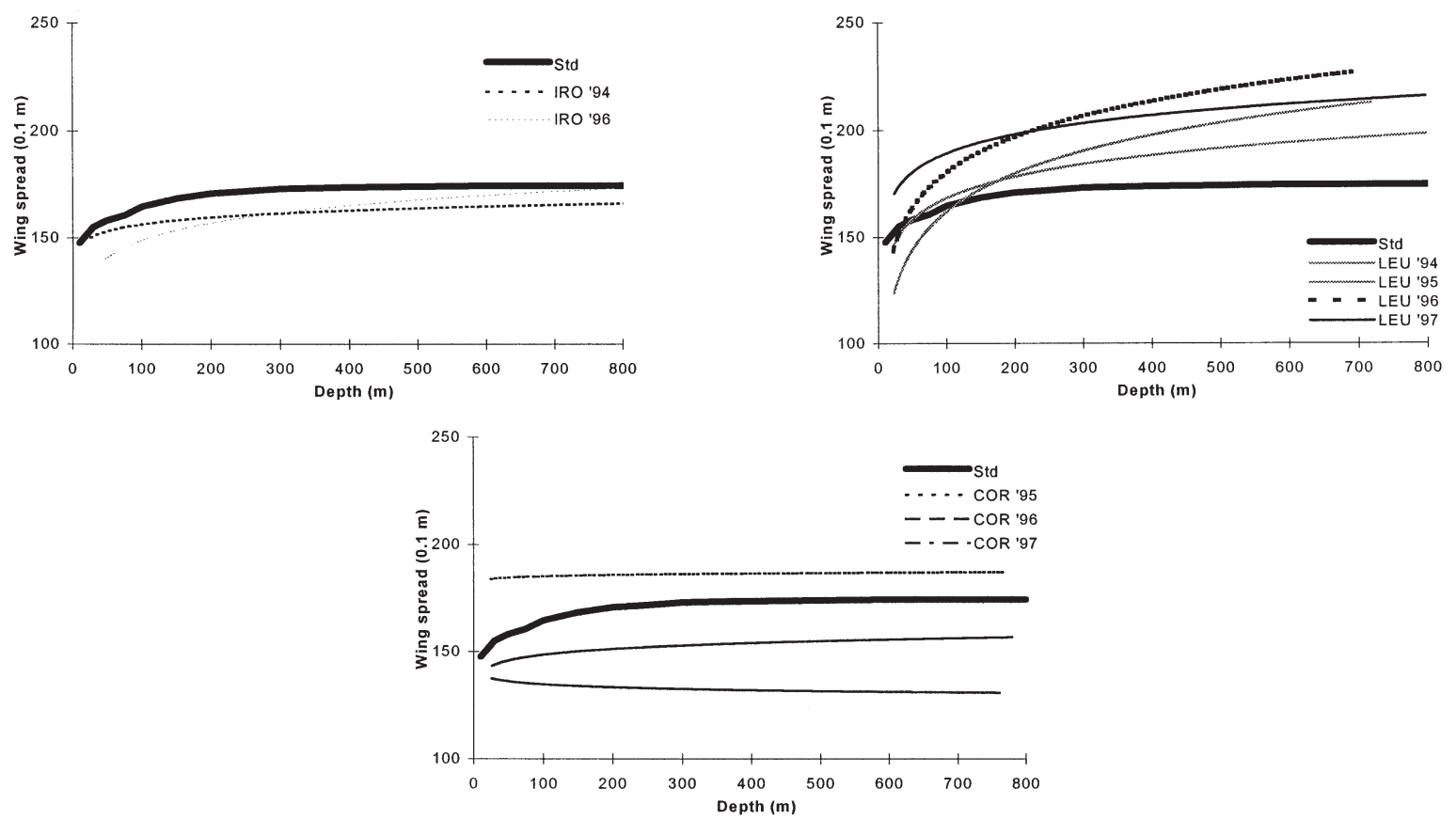

FIG. 10. - Average wing spreads of all the studied vessels/cruises (Std: standard relationship used by the MEDITS teams when no direct wing spread observation is available; IRO: "Ioannis Rosso"; LEU: "L'Europe"; COR: "Cornide de Saavedra").

between the effective haul depth and the one registered at the bridge sounder.

\section{Gear stabilization and geometry}

The example given in Figure 3 illustrates the delay required after the warps are completely paid out and the winch stopped, before the horizontal net opening reaches stabilized measures around the mean value. In the study case, the time needed for stabilization of the net opening was a few minutes (usually less than ten minutes; Fig. 8). This time was strongly affected by the warp length. It increased with warp length and therefore with bottom depth.

After stabilization, the average wing spread was slightly variable between hauls for a same vessel. These intra-vessel variations were partly in relation with depth (Fig. 9a), but not in all cases (Fig. 9b). 
The main intra-vessel variability was a haul-to-haul one. So far, at the same depth, it varied as much as 5 $\mathrm{m}$, i.e. almost 30 percent of the average wing spread, for most of the study vessels. We may emphasize that this situation was not general. For instance, very few haul-to-haul variations occurred down to $200 \mathrm{~m}$ for the two vessels "L'Europe" and "Ioannis Rosso" in 1996 (Fig. 9c). Not surprisingly, the variations in wing spread were inversely correlated with the corresponding vertical opening values, due to the semirigid trawl configuration. For instance, when the mean wing spread was $19 \mathrm{~m}$ aboard the "Cornide de Saavedra" in 1995, the vertical net opening was approximately $2 \mathrm{~m}$. Inversely, with a smaller mean wing spread $(13 \mathrm{~m})$, the vertical opening was about $3 \mathrm{~m}$ aboard the same vessel in 1997.

Beyond this intra-vessel/cruise variability, a variability between vessels and years also occurred (Fig. 10). This variability was in the same scale of size as the haul to haul variations. The standard curve calculated from the asymptotic function indicated earlier was located between the curves drawn from the SCANMAR recordings.

\section{DISCUSSION}

When compared with other available devices, the basic principles of the trawl net make this gear very attractive to sample a wide diversity of demersal and benthic species over soft bottoms (Fernö and Olsen, 1994). Despite the worry about fish behaviour in front of the trawl (Godø, 1994), and that the gear does not sample their whole distribution volume for some of the species caught (Bertrand et al., 2000b), the concept of swept area as an approximation of filtered volume offers facilities to build quantitative biological estimators. These advantages, linked with crew competencies in operating this kind of gear, have incited scientists to extensively use trawls for routine fishery surveys. So, only for the North Atlantic zone and the Mediterranean, we have identified more than twenty outstanding trawl survey series. Nevertheless, the investigations conducted during the last three decades thanks to the availability of gear instrumentation have drawn attention to the variability of trawl performances and their effect on the quality of demersal resources assessment.

Despite efforts to standardize the sampling trawl, its rigging and handling, the MEDITS programme does not avoid this problem. Actually, the results presented above emphasize the need to take the highest care when handling the sampling gear, in order to reduce the uncontrolled variability in estimating the swept area parameters.

Trawl measurements from tows during routine surveys may identify the frequency of "bad" tows, i.e. tows for which the gear was not fully spread or was not on the bottom for a substantial part of the haul. So far, a relative high percentage of bad tows is documented in the literature: 17\% (Engås and Godø, 1986) and 23\% (Engås and West, 1987) in the Barents Sea, 29\% during Pacific cruises off California (Wathne, 1977). The estimate of $6 \%$ of very "bad" hauls from the present trajectory analysis is set inside these values. Nevertheless, it takes into account only one of the parameters contributing in swept area estimates. To improve the swept area estimates, and consequently species abundance and distribution estimates, the variability of each contributing parameter has to be carefully managed and controlled. Furthermore, the validity of each of the hauls for biological assessment must be carefully checked.

The score ratio given in the standard MEDITS protocols (Anon., 1998) has been established for mean values of steel wire weight per length unit and an ordinary bottom. This ratio has to be considered as a guide. Nevertheless, some adjustments can be useful in order to facilitate the descending motion of the trawl and its good contact with the bottom. So far, the type of bottom may justify some adjustments. For instance, on soft bottom conditions, shooting extra warp length in the shallow areas may compensate the higher spreading force to the doors (Godø and Engås, 1989).

A mean value of trawl descent speed, calculated from shooting start to first contact of the net with the bottom may hide some speed variation with depth. We have noted that the descent speed can decrease with increasing depth, particularly down to $300 \mathrm{~m}$. Even if the shooting mode seems to be more determinant, the net descent speed can be also partly determined by the differential in density between the seawater (and particularly the deep ones) and the polyamide used to make the standard trawl, these two density values being close to each other. A trawl built in polyester (density $=1.38$ ), instead of polyamide $($ density $=1.14)$, should perceptibly decrease the net descent time, but its cost would be much more expensive. On some occasions, and probably due to a combination of water density and adverse currents close to the sea bed, the trawl may seem to be lying over a layer of water surmounting 
the bottom. Recordings on water current characteristics at the trawl location should be necessary to understand the process. Whatever the cause may be, crossing this limit to reach the bottom may require some specific bridge/deck operations. For all the deep hauls, the doors undoubtedly reached the bottom a more or less long time before the net itself.

When shooting additional warp length, some different shooting speeds have been tested on several occasions (on a falling bottom) aboard the R/V "L'Europe" during the MEDITS 2000 survey to estimate their effect. There was strong evidence that the faster was the shooting speed, the faster and better was the trawl contact with the bottom. No suggestion was given up to now in the MEDITS protocol concerning the vessel speed during shooting, and the warp shooting speed itself. Future consideration of this subject would be of interest.

Bad estimates in descent speed may induce considerable disagreement between the time of first bottom contact as recorded by field sensors and as determined in the conventional way by the watch officer. In deep water (as far as $600 \mathrm{~m}$ depth), discrepancies of as much as 10 minutes were documented (Engås, 1994; Godø and Engås, 1989 ). This delay is close to the present average of 15 minutes between 200 and $800 \mathrm{~m}$ depth.

Waiting periods, commonly of 5 to 10 minutes or more, to allow the trawl to be fully stabilized, are cited in the literature (Walsh and McCallum, 1995). The same discrepancies were observed from the present analysis (Fig. 8). The trials achieved within the MEDITS program (Fiorentini et al., 1996) to decrease setting time $\left(\Delta \mathrm{t}_{1}\right)$ have shown that many solutions combining vessel speed and warp unwinding may be adopted, making difficult without trawl instrumentation the estimation of the exact tow duration aboard each vessel.

Some authors (West, 1985) (in Engås, 1994) suggest that the required delay for the trawl to come off the bottom at haulback after beginning of warp retrieving may be very variable and unpredictable, ranging from no delay to as much as 5 minutes. In the Mediterranean, due to the usual operating mode, particularly on board commercial vessels, we can anticipate that the trawl does not have efficient speed during warp retrieving. Nevertheless, this phase of the tow may affect differently the catchability of different groups of species (fish, crustaceans, etc.). Anyway, the variability of this parameter is probably of a weak importance regarding the other parameters introduced in the swept area calculation.
This analysis has highlighted the existence of discrepancies in tow characteristics between those estimated by the teams on board and the effective ones. For a better control of the effective towed distance, and when unavailability of direct information on the trawl performance, a trajectory curve could be systematically drawn from depth/time continuous recorders fixed on the net (suggested cadence of recording: one record per minute). This a posteriori curve should be interpreted after each haul to calculate the effective haul duration in contact with the bottom. The start of a haul should be the time of first contact with the bottom, taking into account the delay of gear stabilization (cf. below). The definition of haul end would take into account an eventual continuation of the tow after the beginning of warp rewinding. Furthermore, the estimate of swept distance by the trawl from the towed duration would imply the availability of data to reconstruct the vessel shipping lane minute per minute.

Following many studies in different areas (Doubleday and Rivard, 1981; Engås, 1994; Godø and Engås, 1989), the present analysis has highlighted that, even in the case of standardized sampling gear design from doors to cod end, its rigging and handling, a real wing spread variability may occur at different levels: (i) inside tows in the same soundings aboard one vessel during the same survey/experiment, (ii) inside surveys/periods for the same vessel on the same area, in terms of average wing spread values as far as in terms of inside tows variability, and (iii) inside vessels. As the trawl vertical opening is linked to wing spread, this variability affects not only the swept area estimates, but also the height of water column effectively sampled. Due to the diversity of the species vertical distribution (Bertrand et al., 2000b), this can have a great influence on the species catch composition.

These variabilities have been recognised by many researchers during the few last decades, and several methods have been employed to maintain constant trawl geometry at all fishing depths aboard different vessels (Engås, 1994). One option, as done in the MEDITS survey, was to increase the length of the sweeps (connecting the doors to the spreaders). By this way, it is theoretically possible, but not always confirmed (Hagström, 1987), to hold wing spread constant in spite of increasing door spread. However, the area swept by the sweeps and spreaders may contribute in the total area swept by the gear. So far, sweep length may have an effect on catching efficiency for different length groups of 
fish (Engås and Godø, 1989). Another possibility is to adjust the warp length on a case by case basis. This method implies the availability of direct door or wing spread observation. Finally, to reduce the wing spread variability with depth and vessel, different authors (Engås and Ona, 1991; Engås, 1994; Fréchet, 2000; Rose and Nunnallee, 1998) have suggested and successfully tested the use of a line affixed between the towing warps ahead of the doors to restrict the ability of the trawl to open further when more warp is deployed.

In the Barents Sea, variations in swept area were more associated with variation in depth than with ship-effect (Godø and Engås, 1989). The major external factors responsible for between tows variability were differences in bottom and/or current conditions (Carrothers, 1981; God $\varnothing$ and Engås, 1989). In other experiments in different areas, an actual ship (or captain) effect has been pointed out (Anon., 1990; Walsh and McCallum, 1995). These experiments show that, on the shelf (depth shallower than $200 \mathrm{~m}$ ), the distance effectively swept by the trawl in contact with the bottom was very similar to the one sailed by the vessel, and no correction has to be done on the distance data recorded. The situation was different for deeper bottoms for which a difference in distance is quite common. One of the main objectives of standardized bottom trawl surveys is the production of data series to estimate trends in biological parameters such as abundance indices and size distributions. To take into account the need for maintaining the series consistency, one option should be to leave the survey perpetually in their imperfect state. Some arguments may convince that this approach condones inefficiency (Cotter, 1997). Furthermore, nothing but addition of gear instrumentation may be enough to induce imperceptible changes in its control, and in its performances. So far, if improvements are decided, they have to be carefully managed, strictly avoiding not well documented rough adjustments which could prevent from a clear reconstitution of the series. Furthermore, a schedule should be defined to allow intercalibration between the old and the new survey designs. For this aim, different methods may be applied, from specific intercalibration surveys (Pelletier, 1998) to partial overlap between the two series designs (Cotter, 1997).

Different authors (Byrne et al., 1981; Carrothers, 1981; Godø and Engås, 1989; Walsh and McCallum, 1995) have convincingly shown that failure to monitor trawl performance can result in an increase in the unsatisfactory levels of error in survey indices. Variations of $23 \%$ and $37 \%$ in the abundance indices were estimated in relation to swept area estimates (Godø and Engås, 1989). They have emphasized that direct observations of trawl geometry during all tows are crucial for controlling the swept area in bottom trawl surveys series and for improving abundance indexes estimates. Actually, permanent checking as well as restricting evolution of the standard survey trawls to avoid differences in trawl components are expected to contribute to a reduction of bias and variability in the catching efficiency of various species and size groups (Godø and Engås, 1989; Walsh and McCallum, 1995).

This analysis illustrated and confirmed (i) the need for systematic identification of non-valid hauls and their exclusion from biological studies, and (ii) the necessity for a better estimation of the effective swept area (distance covered in full contact with the bottom and wing spread, specially in the deepest areas) to reduce to more acceptable levels the measurement variability in abundance indices estimates.

When there is an unavailability of other devices, a posteriori information as obtained from depth/time sensor continuous recorders should be systematically stored and used to rectify the haul's information picked up from the bridge. Furthermore, considering the highly-uncontrolled variations in wing spread, the potential advantage of using a constraining rope on the warps in front of the doors should be investigated. Nevertheless, this approach should be considered as a compromise. Actually, from the state of art as well as from present results, we emphasize that a quality strategy to be developed when applying trawl survey methodology for assessment of demersal resources would combine the use of rigorous protocols that cover all aspects of fishing, and systematic controlling and recording of all the main parameters allowing to characterize the trawl performance and the continuity of its contact with the bottom. This approach would gain by jointly involving fishery technologists and biologists in charge of biological resource assessments.

\section{ACKNOWLEDGEMENTS}

The preparation of this paper has been possible owing to the confident contribution of all the teams who have taken part in the MEDITS survey programme and made their data available to us. They 
are warmly thanked for their full support. We also thank the anonymous referees for their very useful suggestions to improve the paper.

\section{REFERENCES}

Anon. - 1990. Report of the international North Sea, Skagerrak, and Kattegat bottom trawl survey working group. ICES C.M. 1990/H:3:1-55.

Anon. - 1998. Campagne internationale de chalutage démersal en Méditerranée (MEDITS) : manuel des protocoles. Biol. Mar. Medit., 5(2): 515-572.

Anon. - 1999. Campagne internationale de chalutage démersal en Méditerranée (MEDITS) : manuel des protocoles. Version actualisée. IFREMER. Project 97/25 IFREMER-CE. 21 p.

Bertrand, J.A., Y. Aldebert and A. Souplet. - 2000b. Temporal variability of demersal species in the Gulf of Lions from trawl surveys (1983-1997). In: J.A. Bertrand and G. Relini (eds.), Demersal resources in the Mediterranean. Proceedings of the symposium held in Pisa, 18-21 March 1998, Actes de Colloques 26, pp. 153-164. IFREMER, Plouzané.

Bertrand, J.A., L. Gil de Sola, C. Papaconstantinou, G. Relini and A. Souplet. - 2000a. An international bottom trawl survey in the Mediterranean: the MEDITS programme. In: J.A. Bertrand and G. Relini (eds.), Demersal resources in the Mediterranean, Proceedings of the Symposium held in Pisa, 18-21 March 1998, Actes de Colloques 26, pp. 76-93. IFREMER, Plouzané.

Bertrand, J., L. Gil de Sola, C. Papaconstantinou, G. Relini and A. Souplet. - 2002. The general specifications of the MEDITS surveys. Sci. Mar., 66(Suppl. 2): 9-17.

Byrne, C.J., T.R. Azarovitz and M.P. Sissenwine. - 1981. Factors affecting variability of research vessel trawl surveys. In: W.G. Doubleday and D. Rivard (eds.), Bottom trawl surveys. Can. Spec. Publ. Fish. Aquat. Sci., 58: 258-273.

Carrothers, P.J.G. - 1981. Catch variability due to variations in groundfish otter trawl behaviour and possibilities to reduce it through instrumented fishing gear studies and improved fishing procedures. In: W.G. Doubleday and D. Rivard (eds.), Bottom trawl surveys. Can. Spec. Publ. Fish. Aquat. Sci., 58: 247-257.

Cotter, A.J.R. - 1997. Can groundfish surveys be improved without breaking the series? ICES CM 1997/Y:24 : 1-9.

Doubleday, W.G. and D. Rivard (eds). - 1981. Bottom trawl surveys. Can. Spec. Publ. Fish. Aquat. Sci., 58: 1-273.

Dremière, P.-Y., L. Fiorentini, G. Cosimi, I. Leonori, A. Sala and A. Spagnolo. - 1999. Escapement from the main body of the bottom trawl used for the Mediterranean international trawl survey (MEDITS). Aquat. Living Resour., 12(3): 207-217.

Engås, A. - 1994. The effects of trawl performance and fish behaviour on the catching efficiency of demersal sampling trawl. In: A. Fernö and S. Olsen (eds.), Marine Fish Behaviour in Capture and Abundance Estimation, pp. 45-68. Fishing News Books, Oxford.

Engås, A. and O.R. Godø. - 1986. Influence of trawl geometry and vertical distribution of fish on sampling with bottom trawl. $J$. Northwest Atl. Fish. Sci., 7(1): 35-42.

Engås, A. and O.R. Godø. - 1989. The effect of different sweep lengths on the length composition of bottom-sampling trawl catches. J. Cons. Int. Explor. Mer, 45: 263-268.

Engås, A. and E. Ona. - 1991. A method to reduce survey bottom trawl variability. ICES CM 1991/B:39.

Engås, A. and C.W. West. - 1987. Trawl performance during the Barents Sea cod and haddock survey: Potential sources of gearrelated sampling bias. Fish. Res., 5(2-3): 279-286.

Fernö, A. and S. Olsen (eds.). - 1994. Marine fish behaviour in cap- ture and abundance estimation. Fishing News Books, Oxford.

Fiorentini, L. and G. Cosimi. - 1981. Some remarks on the Italian bottom trawl. FAO Fish. Rep., 253: 125-129.

Fiorentini, L., G. Cosimi, A. Sala and V. Palumbo. - 1994. Caratteristiche e prestazioni delle attrezzature a strascico impiegate per la valutazione delle risorse demersali in Italia. Biol. Mar. Medit., 1(2): 115-134.

Fiorentini, L., G. Cosimi, A. Sala, I. Leonori and V. Palumbo. 1998. Ulteriori osservazioni sulle prestazioni delle attrezzature a strascico impiegate per la valutazione delle risorse demersali in Italia - Further observations on the performance of the fishing gears used for demersal stock assessment in Italy. Biol. Mar. Medit., 5(3): 156-165.

Fiorentini, L., G. Cosimi, A. Sala, V. Palumbo and I. Leonori. 1996. Intercalibration des campagnes internationales de chalutage démersal en Méditerranée centrale. IRPEM. CE Med/93/015. 59 p.

Fiorentini, L., P.-Y. Dremière, I. Leonori, A. Sala and V. Palumbo. - 1999. Efficiency of the bottom trawl used for the Mediterranean international trawl survey (MEDITS). Aquat. Living Resour., 12(3): 187-205.

Fréchet, A. - 2000. Multiple otter-trawl calibration for the sentinel surveys in the northern Gulf of St. Laurence. In: J.A. Bertrand and G. Relini (eds.), Demersal resources in the Mediterranean. Proceedings of the symposium held in Pisa, 18-21 March 1998, Actes de Colloques 26, pp. 37-45. IFREMER, Plouzané.

Godø, O.R. - 1994. Factors affecting the reliability of groundfish abundance estimates from bottom trawl surveys. In: A. Fernö and S. Olsen (eds.), Marine Fish Behaviour in Capture and Abundance Estimation, pp. 166-199. Fishing News Books, Oxford.

Godø, O.R. and A. Engås. - 1989. Swept area variation with depth and its influence on abundance indices of groundfish from trawl surveys. J. Northw. Atl. Fish. Sci., 9(2): 133-139.

Hagström, O. - 1987. Measurements of door spread and headline height of the G.O.V. trawl during the IYFS 1987. ICES CM 1987/B:14

Lauth, R.R., S.E. Syrjala and S.W. McEntire. - 1998. Effects of gear modifications on the trawl performance and catching efficiency of the West Coast upper continental slope groundfish survey trawl. Mar. Fish. Rev., 60(1): 1-26.

Lin, D., K. Sun, W. Meng and D. Xu. - 1996. Preliminary study on performance of trawl made in Fuqiao of Taicang. J. Fish. Sci. China Zhongguo Shuichan Kexue, 3(4): 99-105.

Marteinsson, J.E. - 1992. Trawl performance during bottom trawl survey: Measurements of wing-spread, door-spread and trawl height. ICES-CM-1992/B:22. 14 p.

McCallum, B.R. and S.J. Walsh. - 1995. Survey trawl standardization used on groundfish surveys. ICES-CM-1995/B:25. 13 p.

Pelletier, D. - 1998. Intercalibration of research survey vessels: a review and an application. Can. J. Fish. Aquat. Sci., 55: 2672-2685.

Rose, C.S. and E.P. Nunnallee. - 1998. A study of changes in groundfish trawl catching efficiency due to differences in operating width, and measures to reduce width variation. Fish. Res., 36(2-3): 139-147

Souplet, A. - 1995. Définition des estimateurs. In: J. Bertrand (ed.), Base de données harmonisées pour les campagnes internationales de chalutage démersal en Méditerranée. Rapport de groupe de travail, pp. 7-10. Contract MED 93/025 IFREMERCE.

Walsh, S.J. and B.R. McCallum. - 1995. Survey trawl mensuration using acoustic trawl instrumentation. ICES CM 1995/B:26. 20 p.

Wathne, F. - 1977. Performance of trawls used in resource assessment. Mar. Fish. Rev., 39(6): 16-23.

West, C.W. - 1985. An examination of variability in the volume swept by bottom trawls used for marine fisheries resource assessment. M. Sc. thesis, University of Washington, Seattle. 